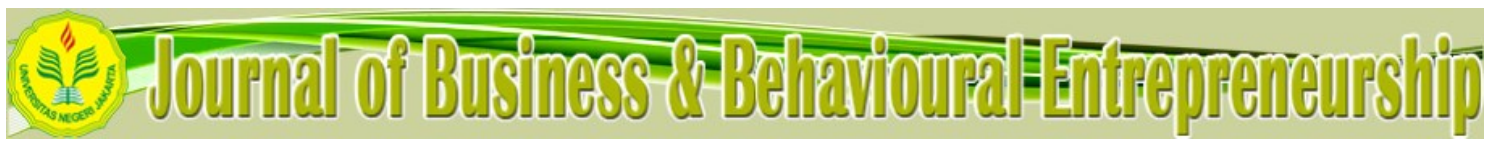

\title{
LEADING WITH COMPASSION IN TIMES OF CHANGES
}

\author{
Muhammad Taufiq Amir
}

Universitas Bakrie

Email: taufiq.amir@bakrie.ac.id

\begin{abstract}
Managers face various challenges and difficulties at work, especially in dealing with changes. The adverse events can be compounded when personal problems also put additional pressure on the manager. The compassionate leader can function to alleviate the stress. This study shows how leading with compassion, where leaders are sensitive to problems, feeling those difficulties, and are motivated to help. By referring to the positive organization literature, aspects, and processes of compassion in organizations are disclosed. Likewise, how compassionate leaders increase the attention and understanding, empathize with the needs of managers and their future are also explained. Furthermore, leaders can also be present in the various policies that they create. This study is useful for making leadership effective, especially in managing organizational change.
\end{abstract}

\section{Keywords: Leading, compassion, organizational change}

Received: 16 November 2021 ;

Accepted: 21 December 2021;

Publish: December 2021

\section{How to Cite:}

Amir, M.T. (2021). Leading with Compassion in Times of Changes. Journal of Business and Behavioural Entrepreneurship, 5(2), 99-107. https://doi.org/10.21009/ JOBBE.005.2.12 


\section{INTRODUCTION}

Running a successful business organization, namely making the business survive and grow, is always full of challenges. In order to succeed, employees must work hard and implement the right strategy. However, this endeavor and the right strategy do not guarantee an organization's success because many things or factors are beyond the employee's control. It is not uncommon for these factors to be disruptive, unpredictable. All this results in challenges and difficulties.

Apart from originating from external factors, which are relatively difficult to control, employee difficulties also arise from internal factors. These internal factors can generally be divided based on work-related such as heavy loads, inadequate facilities, or because other resources are limited (Crawford et al., 2010). Internal factors are also in the form of a poor relationship with superiors, colleagues, or subordinates. Employee problems and difficulties are increased when personal issues are inevitably brought to the office. Having a leader who can reduce or eliminate employee suffering and problems is very important, so it is only natural that academics and practitioners discuss a compassionate leader.

Compassion is formulated as a condition of attention to pain or needs that have not been met by others and at the same time a desire to reduce that suffering (Goetz et al., 2010). Compassion has a lot to do with being sympathetic, kind, gentle, warm, caring, or loving. Leading with compassion is how a person thinks, feels, and acts when facing employees' difficulties (Dutton, Kristin, et al., 2014; Lilius et al., 2012). A compassionate leader is someone aware of a difficult situation in others, feels the difficulty, and assesses the need or is moved to help.

The application of compassion in organizations cannot be separated from positive psychology development in an organizational context (Kanov et al., 2004). Various formulations have been put forward related to compassion, and often like two different things; As motivation, as well as a primary trait, or as a character that can be developed (Goetz \& Simon-Thomas, 2017). Motivation appears with a particular stimulus, such as vulnerability, unnecessary suffering, or unmet needs, and various other sufferings. Some see it more as motivation, the urge to care for, protect, and perhaps fulfill basic needs. In the process, the compassionate person suppresses personal interest, gives attention, and sometimes faces challenges. Researchers are also interested in understanding whether compassion experiences necessarily generate motivation to help people. Some of the questions you want to find out are what facilitates and hinders compassion motivation. Does this experience lead to motivation to help others, what is a facilitator and barrier to motivation? Can this motivation make other people motivated by the same thing?

When compassion is considered a necessary trait, it means someone who repeatedly appears, as a personal value. The habits of thinking and the motivational components that influence a person's general likelihood of experiencing compassion. People who become sensitive, for example, to certain situations. Long childhood experiences such as warmth and coaching from parents and the close relationship obtained from caregivers are also decisive (Goetz \& Simon-Thomas, 2017).

Leaders have an important role because their messages and actions have an impact. Especially in times of stress, organizations need leaders who carry hope with their vision and also to manage frustration and anxiety. Several studies demonstrate the benefits of compassion in organizational contexts; help restore employees or organizations from trauma (Vanette et al., 2006), creare a positive climat that is important for performance (James \& Wooten, 2011), build mutual trust, motivation and relationships 
(Stephens et al., 2013) or even benefits for customers (Simpson et al., 2014).

Although many have researched leadership with useful traits, it is still rare to say that deepening the abilities and skills related to suffering and compassion are still rare. In his speech at the management academy in 2012, Tsui (2013) encouraged practitioners and academics to explore compassion further, because its relevance to the corporate world is very high.

This article examines the aspects associated with compassionate leadership. Leaders who can interpret the conditions of the difficulties around them are sensitive to the challenges and will then act to solve the problems. The compassion process model in organizations is discussed in the following subsections. After that, the process is further detailed by linking to leadership roles. The final section discusses the elements of acting from the compassion leader, both direct and in the form of policies or regulations.

\section{RESULTS AND DISCUSSIONS}

\section{Compassion Process in Organizations}

One reasonably comprehensive model describing compassion in an organizational context is from Dutton et al. (2014). In this model, compassion is considered as a process in an organization that is related to paying attention, interpreting, and understanding someone's suffering. This process affects feelings and motivation and actions taken in response to that suffering. In their follow-up study, Worline and Dutton (2014) added a social aspect so that the formula is a social process rather than just individual emotions. Compassion is characterized as a four-part process; 1). Care for suffering, 2). Understanding suffering, 3) feeling empathic, and 4) taking action to reduce suffering. The following sections elaborate on this compassion process.

\section{Attention \& Understanding}

\section{Attention}

The problem of leaders' attention to employees, especially attention to difficulties, is central in compassion. Doing so demanding job, facing complicated issues, or is being required a high quality of work, leaders have the potential to neglect to pay attention to the suffering around them. Study Chapman and Sisodia (2015), found that in America, 88\% of employees, or about 130 million people, come home from work feeling that they work for companies that don't listen to them. This data shows that there is indeed something wrong with concern for employees, and of course, partly a matter of difficulty. In fact, a successful leader makes his company progress is a leader who touches the problems faced by his employees, including their problems.

Busyness, pressure, and focus on other matters of a more material nature, such as achieving specific goals, will obscure the attention and understanding of the employee's difficult situation. Fiske (1993) found that superiors who have a high position and status tend to pay less attention to the nuances that occur to those around them and more rely on stereotypes rather than more meaningful information. Stress and serious challenges can make someone's attention to human aspects, and other people psychologically less.

With the disruption of one's attentions, Goleman (2009) suggests leaders in- 
crease the ability to focus so that concentration is also increased. One of them is understanding the brain's mechanism of paying attention so that leaders or employees also need to be aware of related disturbances. Inattention, emotions are essential, because our attention is very much determined by feelings. The distraction of emotion, ruminating, i.e., thinking about a problem repeatedly instead of imagining a solution, is much more distracting to paying attention. When a person can overcome his emotional distress, such as, then he can also increase attention, and in time to understand the difficulties.

On the other hand, expressing difficulties is also not necessarily easy for employees. Various factors play a role in preventing a person from expressing their problems. For example, concerns that arise due to role expectations or professionalism. Because of certain targets or norms, a person feels inappropriate to admit the difficulties he is facing. Personal concerns are also an obstacle because it requires a close relationship and interaction techniques (Dutton, Workman, et al., 2014). The leadership context also plays a role when the atmosphere is less open, and leaders fail to create a flexible and safe psychological climate for employees to convey their problems (Atkins \& Parker, 2012).

The mechanism for giving attention, as explained above, cannot be separated from the process of understanding, in which there is meaning. Understanding and meaning are what makes the compassion process turn to feelings and empathy to then proceed to action. Different interpretations will produce different feelings. Leaders have the potential to form a collective meaning or suffering, which ultimately leads to empathy.

\section{Empathy}

Empathy can be the main component in compassion and is the beginning of the motivation to act to reduce difficulties. As part of the compassion process, various researchers also formulated empathy. Baston (2017) says that empathy encompasses a concept related to the process by which a person understands, shares, or feels moved by a person's physical or emotional condition. There are also those who think that empathy is divided into two; cognitive empathy; when people accurately understand other people's perspectives, try to understand their feelings and thoughts; and affective empathy or emotional empathy, where people feel what other people think. This can happen by imitating someone for something that is physically visible.

This discussion is inseparable from the term "contagious emotions" (Boyatzis $\&$ Soler, 2012). Organizational studies on the emotional aspects of culture by Barsde \& O'Neill (2014) show that "the culture of companisonate love," which shows concern, warmth, and love for employees, plays an important role in the success of work culture.

In short, empathy is related to being sensitive to other people's feelings in response to their expressions and understanding what other people feel and why. Empathy is more about feeling things; pride, anger, grief, or joy. On the other hand, compassion is more specific about suffering and sorrow. Empathy also recognizes that there is an urge to act, whereas compassion has an element of wanting to do things that reduce the suffering of others. Empathy is often associated with emotionally oriented people, such as feeling thoughts, imagining thoughts, and feelings (Batson \& Ahmad, 2009). 
Empathy may have something to do with a person's personality (Batson, 2017). Life experiences, childhood, environment that affect the basic pattern of a person. But it also means that the problem, atmosphere, or organizational climate can be an essential context in empathy. When the prevailing climate is an independent attitude, relying heavily on independence, rather than interdependence and helping each other, compassion is difficult to come. More criticism is present when difficulties are exposed.

Apart from personality, the context of the situation also plays a role in the presence of empathy. When the environment is not supportive, a person's personality tendency to empathize can get hindered. Studies on abusive behavior in the workplace, for example, show that when rudeness, harsh criticism, and embarrassment characterize a leader, compassion goes further (Porath \& Pearson, 2013). Leaders need to create a context that facilitates empathetic concern so that, in the end, it allows for motivation to help.

\section{Present and Future Needs}

A compassionate leader is not only concerned with "present" needs but also to shadows future needs. Future needs are related to the elements of a person's growth, and in this, leadership should stand out. This is relevant to the phrase "good leaders give birth to new leaders." Boyatzis (2006) who developed the intentional needs theory, recently showed compassion as part of a leadership model, which he called "resonant leadership" (Boyatzis, Smith, Van Oosten, et al., 2013). Recently, with the support of neuroscience Boyatzis and his colleagues again offered to coach with compassion. In the context of coaching, compassion, according to Boyatzis et al.(2013) a is an interpersonal process that pays attention to the needs of others, empathizes with, and acts to improve their well-being in response to these needs. And this is an important part of coaching with compassion.

Compassion here is not just a hardship in the present, but because of evolving needs and the future. The point is coaching with sincerity and care, which focuses on others, provides support and encouragement, and facilitates the discovery and achievement of one's dreams and passions (Boyatzis et al., 2019).

Coaching with a compassion approach focuses on awakening someone's ideal, initiating, and guiding someone in this process. The ideal figure is a vision, what a person's goal is to become, the values and deepest aspirations for the future (Boyatzis, 2008). Leaders who practice this approach emphasize the strengths of the moment while still considering existing weaknesses. Coaching, in this way, builds a trusting relationship that creates a comfortable atmosphere to discuss hopes and dreams more openly and comfortably with new thoughts and behaviors.

\section{The Element of Acting Compassionate}

Leaders usually have access to resources and authority so that they can do two things in acting on compassion. First, behave directly when interacting with employees who are suffering and need help. Second, building a context for the surrounding environment, through various policies that facilitate attention and emphasize the creation of the meaning of compassion, and also create an atmosphere for people to be more empathetic, and actions that reduce suffering (Worline \& Dutton, 2017). These two things are expected to be able to color, becoming a "dominant ingredient" for thinking patterns and acting in organizations. The interaction of superiors and employees is not 
seen about individual and hierarchical matters, but rather how it can increase attention, understanding, and compassion action.

In carrying out these two elements of action, the resources involved can vary. It could be material such as money and other goods; it could be psychological resources or an idea. The activities of giving, receiving, and witnessing a compassionate action process can generate new resources with a strong emotional closeness and commitment within the organization (Bushe, 2013; Lilius et al., 2008).

The following section will discuss action strategies that are extracted from Worline and Dutton (2017).

\section{Presence with Expression and Action}

In addition to paying attention and helping people around who are always interacting, a leader also needs to show his presence in moments of difficulty. When someone is grieving, for example, there is a disaster or a family member is sick or dies, a leader shows his presence. As discussed above, suffering or hardship can come from work: failure to meet targets, demands for change, violence, assault, violence, and aggression or abuse from employees, customers, or even suppliers. Also demands for growth, as well as joint dysfunction (Porath \& Pearson, 2013). Or other inevitable things outside of work such as loss, pressure, or accidents. Because the sources of suffering are many, creating a space for employees to express their pain builds trust, authenticity, and a sense of caring. Apart from showing an immediate presence, this can also be done through other communication channels such as telephone or social media messages.

His presence to show compassion via social media was demonstrated by a director of a State-Owned Enterprise in the field of plantations based in Jakarta. He is used to delivering grief messages, both for the difficulties experienced by his subordinates, colleagues, and even partners. This action shows that he pays attention, emphasizes togetherness, and ignores differences in status. Actions and expressions like this show the leader's behavior is the manifestation of the organization providing room for various things openly, including for things that are suffering. More than just paying attention, the company can certainly be further involved, such as providing condolence money when an employee's family member dies. In articles or video media about businesses that are becoming popular, they explain this. For example, the case of Jeff Weirner, CEO at LinkedIn, when he paid attention to employees who were expatriates of his company so that their immigration problems were smooth and prepared, assisted, and facilitated (Weiner, 2012).

By acting directly with compassion, a leader will be a model for his employees. Becoming a model in acting, especially when prioritizing resolution of employee difficult situations, in line with the concept of serving leadership, namely placing priorities and showing empathic action on employee problems (Liden et al., 2014)

\section{Acting Through Policy}

Organizations with many employees or geographically separated leaders find it difficult to interact directly with their employees. In situations like these, however, leaders have limitations to function as models of compassionate behavior. It can act through the design of policies that ensure structurally, and resources can be directed to facilitate compassionate action. The resulting policies are required to make employees 
feel safe, supported, and feel facilitated (Worline \& Dutton, 2017).

The case of the Facebook company can be an example of an application worthy of consideration to show the concern of company management. This company changed the norm, providing 20 days of leave for employees who mourn a family member (Miller, 2019). Another company, Cascade Engineering is known for its recruitment activities that also feature compassion. One that is quite successful is the "Welfare-tocareer track" program, where they manage a special program to recruit and manage employees who come from the poor (Gerrish \& Samber, 2017). Other policies, employee placement, employee development, retirement are also carried out with a similar approach. In short, the functions related to HR management play a very close role, and this can relate to the strategic needs of the company because leaders have access and control over resources, time, money, and connections. In fact, for everyday matters such as making decisions, compassion can also be considered.

In various decision-making processes, a leader has the opportunity to explicitly show his concern for the suffering of employees. In the study of Lilius, Kanov et.al. (2012), show examples where leaders pay attention to the suffering of colleagues by using collective decision-making processes related to workloads. How leaders bring attention to daily problems and difficulties, interact with existing units and discuss which parties need attention and assistance, and how to allocate them properly. By doing the things above, the leader also serves as a model for compassion action.

\section{CONCLUSION}

The leader of an organization plays a very broad role in shaping the way employees think and act, including compassion. Compassion is the process of how a person understands, pays attention to, feels, and helps others who are struggling and have needs. It is not only present needs that can be met, but also includes future needs. Leaders have a role in every stage of the compassion process. Starting from the process of understanding because it requires meaning, to becoming a model when he acts directly. This action will be generative, as well as the impetus for other employees to act, think, and act compassionately. To have a broader impact, a leader can create policies that are supportive of a more compassionate climate. Both policies related to HR management can show a leader, and also the company offers its presence, is involved, facilitates, and facilitates all related difficulties. In time, with direct action or through policy, companies can benefit from a compassionate leader, such as high productivity, a sense of belonging as well as closeness and trust between leaders and employees.

\section{REFERENCES}

Atkins, P. W. B., \& Parker, S. K. (2012). Understanding individual compassion in organizations: The role of appraisals and psychological flexibility. Academy of Management Review, 37(4), 524-546. https://doi.org/10.5465/amr.2010.0490

Batson, C. D. (2017). The Empathy-Altruism Hypothesis: What and So What? In E. Seppälä, E. Simon-Thomas, S. L. Brown, M. C. Worline, C. D. Cameron, \& J. R. Doty (Eds.), The Oxford Handbook of Compassion Science (pp. 1-25). The Ox- 
ford University Press. https://doi.org/10.1093/oxfordhb/9780190464684.013.3

Batson, C. D., \& Ahmad, N. Y. (2009). Using Empathy to Improve Intergroup Attitudes and Relations. Social Issues and Policy Review, 3(1), 141-177. https:// doi.org/10.1111/j.1751-2409.2009.01013.x

Boyatzis, R. E. (2006). An overview of intentional change from a complexity perspective. Journal of Management Development, 25(7), 607-623. https:// doi.org/10.1108/02621710610678445

Boyatzis, R. E. (2008). Leadership development from a complexity perspective. Consulting Psychology Journal: Practice and Research, 60(4), 298.

Boyatzis, R. E., Smith, M. L., \& Beveridge, A. J. (2013). Coaching With Compassion. The Journal of Applied Behavioral Science, 49(2), 153-178. https:// doi.org/10.1177/0021886312462236

Boyatzis, R. E., Smith, M. L., \& Van Oosten, E. (2019). Helping People Change: Coaching with Compassion for Lifelong Learning and Growth. Harvard Business Review Press.

Boyatzis, R. E., Smith, M. L., Van Oosten, E., \& Woolford, L. (2013). Developing resonant leaders through emotional intelligence, vision and coaching. Organizational Dynamics, 42(1), 17-24. https://doi.org/10.1016/J.ORGDYN.2012.12.003

Boyatzis, R. E., \& Soler, C. (2012). Vision, leadership and emotional intelligence transforming family business. Journal of Family Business Management, 2(1), 2330. https://doi.org/10.1108/20436231211216394

Bushe, G. R. (2013). Generative process, generative outcome: The transformational potential of appreciative inquiry. Advances in Appreciative Inquiry, 4, 89-113. https://doi.org/10.1108/S1475-9152(2013)0000004003

Chapman, B., \& Sisodia, R. (2015). Everybody Matters: The Extraordinary Power of Caring for Your People Like Family. Penguin.

Crawford, E. R., LePine, J. A., \& Rich, B. L. (2010). Linking job demands and resources to employee engagement and burnout: A theoretical extension and metaanalytic test. Journal of Applied Psychology, 95(5), 834-848. https:// doi.org/10.1037/a0019364

Dutton, J. E., Kristin, M., \& Ashley, R. (2014). Compassion at work.

Dutton, J. E., Workman, K. M., \& Hardin, A. E. (2014). Compassion at Work. A nnual Review of Organizational Psychology and Organizational Behavior, 1(1), 277304. https://doi.org/10.1146/annurev-orgpsych-031413-091221

Fiske, S. T. (1993). Controlling other people: The impact of power on stereotyping. American Psychologist, 48(6), 621-628. https://doi.org/10.1037/0003066X.48.6.621

Gerrish, B., \& Samber, A. (2017, August). Can compassion cure your retention woes. MiMfg, 10. http://mag.mimfg.org/mag/0815310001502810761

Goetz, J. L., Keltner, D., \& Simon-Thomas, E. (2010). Compassion: an evolutionary analysis and empirical review. Psychological Bulletin, 136(3), 351-374.

Goetz, J. L., \& Simon-Thomas, E. (2017). The Landscape of compassion definitions and scientific approaches. In E. M. Seppälä, E. Simon-Thomas, S. L. Brown, M. C. Worline, C. D. Cameron, J. R. Doty, J. L. Goetz, \& E. Simon-Thomas (Eds.), The Oxford Handbook of Compassion Science. Oxford University Press. https:// doi.org/10.1093/oxfordhb/9780190464684.013.1

James, E. H., \& Wooten, L. P. (2011). Orientations of Positive Leadership in Times of Crisis. In Kim Cameron \& Gretchen Spreitzer (Eds.), The Oxford handbook of Positive Organizational Scholarship (pp. 882-894). The oxford University Press.

Kanov, J. M., Maitlis, S., Worline, M. C., Dutton, J. E., Frost, P. J., \& Lilius, J. M. 
(2004). Compassion in organizational life. American Behavioral Scientist, 47(6), 808-827.

Liden, R. C., Panaccio, A., Meuser, J. D., Hu, J., \& Sandy, J. (2014). Servant Leadership : Antecedents, Processes, and Outcomes. In D. V Day (Ed.), The Oxford Handbook of Leadership and Organizations (Issue August 2018, pp. 1-41). The Oxford University Press. https://doi.org/10.1093/ oxfordhb/9780199755615.013.018

Lilius, J. M., Kanov, J., Dutton, J. E., Worline, M. C., \& Maitlis, S. (2012). Compassion Revealed: What We Know About Compassion at Work (and Where We Need to Know More). In K. S. Cameron \& G. M. Spreitzer (Eds.), The Oxford Handbook of Positive Organizational Scholarship. Oxford University of Press. https://doi.org/10.1093/oxfordhb/9780199734610.013.0021

Lilius, J. M., Worline, M. C., Maitlis, S., Kanov, J., Dutton, J. E., \& Frost, P. J. (2008). The contours and consequences of compassion at work. Journal of Organizational Behavior, 29(2), 193-218.

Miller, S. (2019). Facebook's Generous Bereavement Leave Sets a High Standard. SHRM Online. https://www.shrm.org/resourcesandtools/hr-topics/benefits/pages/ facebook-bereavement-leave.aspx

Porath, C., \& Pearson, C. (2013). The price of incivility: Lack of respect hurts morale - and the bottom line. Harvard Business Review, 91(Jan-Feb), 114-121.

Simpson, A. V., Clegg, S. R., Lopes, M. P., e Cunha, M. P., Rego, A., \& Pitsis, T. (2014). Doing compassion or doing discipline? Power relations and the Magdalene Laundries. Journal of Political Power, 7(2), 253-274. https:// doi.org/10.1080/2158379X.2014.927684

Stephens, J. P., Heaphy, E. D., Carmeli, A., Spreitzer, G. M., \& Dutton, J. E. (2013). Relationship Quality and Virtuousness Emotional Carrying Capacity as a Source of Individual and Team Resilience. The Journal of Applied Behavioral Science, 49(1), 13-41.

Tsui, A. S. (2013). On compassion in scholarship: Why should we care? In Academy of Management Review (Vol. 38, Issue 2, pp. 167-180). https://doi.org/10.5465/ amr.2012.0408

Vanette, D., Cameron, K. S., \& Powley, E. (2006). Implementing positive organizational scholarship at Prudential.

Weiner, J. (2012). Managing compassionately. LinkedIn.Com (October 15). https:// www.linkedin.com/pulse/20121015034012-22330283-managing-compassionately

Worline, M. C., \& Dutton, J. E. (2017). How Leaders Shape Compassion Processes in Organizations. In E. M. Seppälä, E. Simon-Thomas, S. L. Brown, M. C. Worline, C. D. Cameron, \& D. Doty (Eds.), The Oxford Handbook of Compassion Science (pp. 1-39). The oxford University Press. https://doi.org/10.1093/ oxfordhb/9780190464684.013.31 